\title{
Service Model for the Service Configuration
}

\author{
Jose Angel Lakunza, Juan Carlos Astiazaran, and Maria Elejoste \\ Design and Production Process Business Unit, Ikerlan S.Coop. Technological Center, Spain \\ \{Jalakunza, jcastiazaran, melejoste\} @ikerlan.es
}

\begin{abstract}
Service is a concept difficult to define. It has been extensively used in different contexts. According with literature a service can be seeing: as an activity or as an output of a process.

By service customization we mean the definition and adaptation of a service according to the customer' requirements, when this customization process is carried out in a systematic way.

A company can respond to user needs diversity offering services than can be customized easily, and/or increasing the service variety offered to the market. The increasing in the service offer variety raises also the variety and complexity in the company transactions that involves cost increments for these transactions. Therefore, the challenge will be to extend the range of services offered to the market maintaining the efficiency, that is similar to the Mass Customization concept.
\end{abstract}

Keywords: Service configuration, Service model, Service personalization.

\section{Introduction}

The importance of service industry in the economy is growing ([3]). Customers are demanding services that meet their needs. The differences between goods and services are fuzzy as it has been argued that products always contain a service dimension. Human needs are satisfied not only with physical goods but also services.

Different authors argue that research on service customization is sparse and needs to be developed in depth ([2]). In the other hand, due to the service nature, it should be adapted to the customer needs.

Our research goal has been focused on the service customization. The main research questions we try to answer are:

\section{- What are the different configuration moments in the service life cycle? \\ - How can we define a generic "Service Family" model?}

First we made a literature review on the service concept. Next, we developed a service classification. After that, we focused on the definition of a generic model for the services that might be configured taking into account the customer needs. And finally, we analyzed the applicability of configuration along the service life. 


\section{$2 \quad$ Literature Background}

Service is a difficult term to define, because it is extensively used in different contexts. This difficulty has been widely mentioned in the literature by different authors ([3], [9]), and using different definitions for the service concept ([11], [3]).

According to [8] two main streams can be identified in the service definition literature: from the service provider's view as an activity (service) and from the customer view as an output of a system (service result).

Reference [9] mentions these different approaches. The provider sees the service offering in terms of process, related to service operation. On the other hand, the customer views it as a service outcomes. As an output a service represents what a customer receives. As an activity it represents how a customer receives the service.

According with [6], configurable services are services that can be customized to individual specifications by means of a set of options to meet a predetermined range of customers needs. Some examples can be: insurance agreements; machinery maintenance contracts; mobile subscriptions; traveling trips; etc.

Increasing the service offering in order to allow the service customization, increases the complexity of the company's operations. The challenge is to broaden the range of the services offered without risking performance [13] that seems similar to the Mass Customization concept as was established in [16].

Taking into account the active role of the customer, a service model has to be customer oriented. It is easily realized that a natural way of customizing a service is along the course of customer service experience.

Modularization as a way to customize services seems not to be a wide research subject. Nevertheless, using and matching modules in response to customer needs has been proposed in [14] and [15]. Reference [4] discusses the pros and cons of breaking down a service into its components. For that the designer should identify the different service elements and check them against the customer' needs. That means that modularity is an area for future research in service development [12]. Modularization seems as one way to achieve service customization.

Literature describing the support of existing configurators in the service configurations is very limited. The ILOG JConfigurator [10] and the CAWICOMS Workbench [1] are examples of product configurators that support the configuration of both goods and services.

\section{Process Map}

The figure 1 represents the process map that can be executed along the service life cycle. As we can see, we have defined three different process levels depending in the time horizon for the process:

- Process level with large time horizon. The input for the process is the market requirements and the output is also the offer to the market. At this level we can distinguish the process for the service strategy definition and the process for the service framework definition for the market (for instance the definition of the city bus lines and timetables). 
- Process level with a medium time horizon. In this case the input for the process is the customer needs and output for the process is the service level agreement (SLA) for the customer. At this level we can see the process for the development of the SLA bid and the process for the development of the service platform. Both processes are framed by the framework defined in the previous level (for instance the definition of the car insurance conditions for a customer).

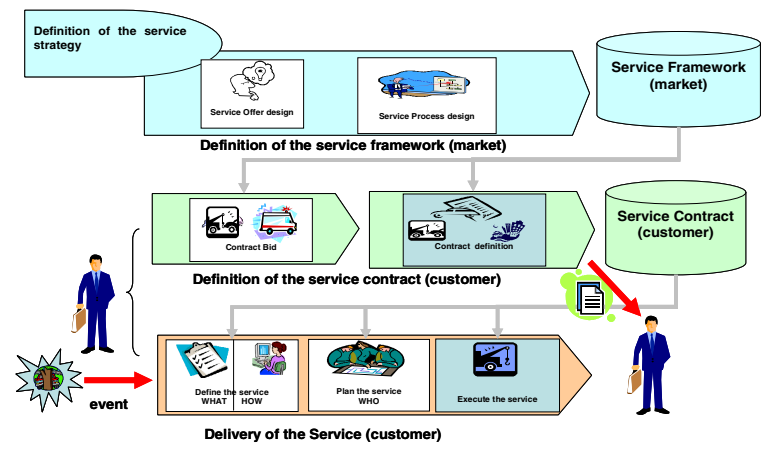

Fig. 1. Process Map

- Process level with a short time horizon. In this case the input is an event for the customer and the output is the executed service for the customer. At this level we can see the following activities in the process for the delivery of the service: definition of the facts for the service and the activities needed to execute the service (WHAT \& HOW); definition of the resources to execute the service (WHO); and the execution of the service itself. These activities are framed by the framework (contract) defined in the previous level (for instance the response for a car accident from the insurance company).

\section{Service Configuration}

In order to answer the possed question what are the different configuration moments in the service life cycle?, we have identified two different service contexts from the point of view of the service configuration: services without SLA definition and services that need SLA definition.

\subsection{Configuration of Services without SLA Definition}

When the company doesn't define a service level agreement (SLA) for the customer, the service framework is the same for any customer that wants the service. That means the company has defined a general framework for the service offer.

In this case, firstly the company defines a general framework for the service, and after that, the company sells an instance of service to a customer, according with the specifications required for the customer. 
The configuration of the service is carried out during the sale and specification definition of the service from the required needs of the customer. This service configuration takes into account the service offer defined previously by the company. In fact in this moment the process needed to answer to the customer requirement is configured (HOW) and also the type of resources needed to execute the process.

In this scenario of services, there is only a configuration possibility for the service: at the moment of specification definition and sale of the service. An example of this service could be the mail service. In this case the customer defines the specifications for the mail at the same moment that pays for the service.

\subsection{Configuration of Services with SLA Definition}

In the field of services, there are a lot of examples in which is necessary to define previously a service level agreement (SLA) for the customer, establishing the characteristics of the service to be provided in the future to the customer. Some examples are insurance services, maintenance services, etc.

In these cases of services we can distinguish three different moments along the service life cycle:

1. Service offer definition for the market.

2. SLA definition and sale for the customer

3. Customer event turn up and service execution for the customer

How does it works in the case of car insurance?. In a first moment, the company defines the overall service offer for the insurance of a car (1). Next, the customer in collaboration with the company defines a specific SLA for the insurance of the customer's car, mentioning all the options covered by the company (2). Once the SLA has been established, as response to any kind of event suffered by the customer (an accident, a car breakdown, etc.), the company provides the customer with the adequate service (3).

In this scenario, two different service configuration moments can be identified along the service life cycle:

- A first moment is the configuration of the SLA itself, taking into account the customer requirement for the SLA and the overall service offer defined for the company. This kind of configuration is quite similar to the used for the configuration of goods. Defines WHAT is going to be provided by the company. For instance when a customer establish with the insurance company the SLA for the car insurance

- In a second moment the company, as a response to a customer event, configures the service process to be execute (HOW), and the kind of resources to be used, taking into account the framework posed by the SLA. For instance when the customer suffers and accident with his car and the insurance company provides the adequate service 


\subsection{Service Execution Planning}

Apart from the configuration of the service contract (WHAT the contract covers) and when an event happens, HOW is going to be delivered the service (the configuration of the process for the service), taking into account the event characteristics and the service contract defined for the customer and the defined type of resources to be used for the execution of the process.

Alter this definition and in order to execute the defined service in response to an event, we must to define exactly which are the resources to be used in the service process (WHO) and when this resources are going to be used (the scheduling). That means two different activities:

- To find resources in the supplier's network: from the information generated as result of the service configuration (HOW the service will be executed and the type of resources needed for the execution of the service) and taking into account the resources available in the network of suppliers, its finds the appropriate resources for the service execution.

- To allocate resources for the service process: once identified the resources, these will be allocated to the corresponding service process activity and the scheduling will be defined. As result of this we will have the customized service process with the allocated resources plus the execution scheduling for the service.

\section{$5 \quad$ Service Model}

According with [4], the service should describe what are the customer needs, how this is going to be achieved, and with what kind of resources. The breakdown of a service into its components, allows the designer to check them against the customers' needs. This approach is necessary in order to customize services in a mass customization schema.

Reference [14] is using product platform concepts that have been used for physical products. Applying modularization techniques to the service is seen as one way to achieve service customization. As in the case of goods, modules can be combined in response to specific customer needs. Usually these service modules are seen as work tasks, parts of processes or groups of activities.

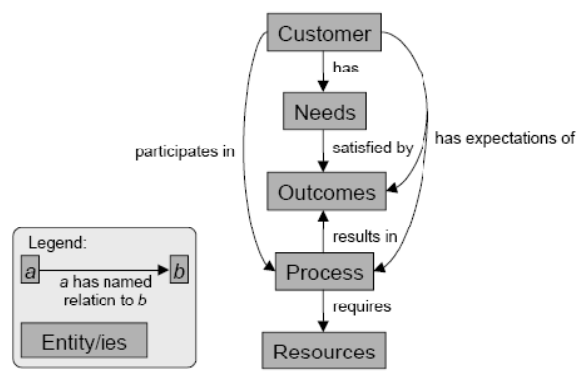

Fig. 2. Conceptual model of services 
The figure 2 shows a high level conceptualization of service proposed in [5] as the result of the service literature analysis.

The aim of our work has been to apply the ideas of Product Family Architecture (PFA) developed in [7] in the field of services, in order to define a service architecture that can be used by a service configurator. Our approach for the definition of this service architecture is based in the analysis of the different moments identified in the service life:

- Definition of the service offer to be provided by the company.

- Definition of the processes to be carried out inside this service offer

- Sale of a service contract

- Specification of the service to be provided to the customer as response to an event

- Planning and scheduling of the service

As the result of our work we propose a service model to answer the question how can we define a generic service model that represents a "Service Family"?.

Our proposal for the conceptual service model derives from that proposed in [5].

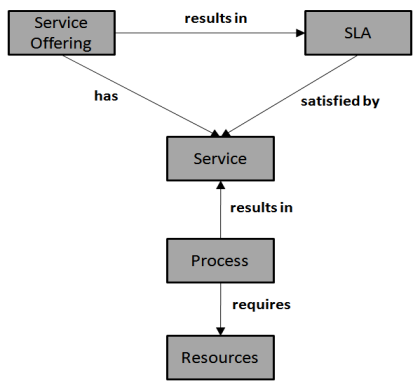

Fig. 3. Conceptual model proposed

In this model each one of the elements that appear in the figure 3 is defined as:

- Service Offering: framework offered by the company to the market (service family).

- SLA (Service Level Agreement): represents the negotiated agreement between the customer and the service provider.

- Service: service element that can be offered by the company to a customer. This service element will be the results of a process.

- Service Process: Services are produced by processes. It represents the set of activities to be carried out to give a service to a customer.

- Resource: element needed to execute the process associated to a service. Resources can be material or human.

The service offering framework for a company represents the company offer to the market that can be customized to the customer needs. This customization of the service offered to a customer will be embodied in as a Service Level Agreement. It records a common understanding about services, priorities, responsibilities, guarantees, and warranties. 
This service offering and its instances (SLA) is made up of elementary services.

Each elementary service will be characterized by several parameters. Every parameter will be constrained to a domain of values. In some cases and as a decision of the company, a parameter will have a fixed value that cannot be changed for the customer.

Each elementary service belongs or not to the service offering depending on a condition or rule.

Moreover, in the proposed model we can establish dependence relationships of different types between the services that take part of the service offering.

How the service can be seen depends on the point of view of the user. The point of view of the customer and the point of view of the company are not the same. Also from the company point of view there are differences between design and production.

From the customer point of view, the service will be defined by its different functions and options and by the list of parameters and value domain for each one.

On the other hand, form the company point of view the service will be defined by the processes, activities and resources needed to deliver the service.

According to this, each elementary service has been broken down into service modules (problems to be solved) and each one will be solved following different variants (service variant).

Each one of the defined service variants will have a process variant to be executed and also needs a resource to deliver the service variant. The set of process variants makes the whole process for the service.

Furthermore, each process variant will be made up of tasks that are broken down into activities.

Taking into account this model, the customization of a service entails the selection of the different service modules needed for the service and for each one of the modules, the selection of the service variant to be delivered to the customer. The sum of these selected variants will put together the service to be delivered.

\section{Conclusion}

As result of our research goal, we have answered the main research questions posed:

- how can we define a generic "Service Family" model?;

- what are the different configuration moments in the service life cycle?.

Answering the first question we have defined a service architecture that allows the model of services that can be customized to the customer needs and that takes into account the two aspects posed by the literature: service as an outcome and service as a process.

To answer the second question we have identified the different moments for the service configuration in the two different scenarios of the service: service without contract and service with contract.

These developments has been tested, during the 2012, in lab cases and later on will be tested in real cases of services. 
As future work we are going to go deeply into the following:

- To adapt the configurator tool developed for the configuration of goods (physical products) to the configuration of service contracts.

- To develop new configurator tool for the configuration of the service processes to be executed by the service provider company, as answer to the event.

As result of this work, we have been able to apply this approach to a company leader in the Spanish lift sector, that provides maintenance services. In this scenario the maintenance service is a complex task for the company: the process depends on the lift; it changes with the year month and each maintenance worker must to carried out the maintenance of a big amount of lifts.

We have modeled the maintenance service and using a configurator tool, we have provided the maintenance worker with a tool that automatically creates the maintenance process to be carried out for each specific lift. That helps the worker in the execution of the maintenance service.

\section{References}

1. Ardissono, L., Felferling, A., Friedrich, G., Goy, A., Jannach, D., Schafer, R., Zanker, M.: A Framework for the Development of Personalized, Distributed Web-Based Configuration Systems. AI Magazine 24(3), 93-108 (2003)

2. Borenstein, D., Silveira, G., Fogliato, F.S.: Mass Customization: Literature review and research directions. International Journal of Production Economics (2001)

3. Fitzsimmons, J.A., Fitzsimmons, M.J.: Service Management - Operations, Strategy, and Information Technology, 4th International edn. McGraw-Hill (2004) ISBN 0-07- 121457-7

4. Goldstein, S.M., Johnston, R., Duffy, J.A., Rao, J.: The service concept: the missing link in service design research. Journal of Operations Management (2002)

5. Heiskala, M.: A conceptual model for modeling configurable services from a customer perspective, Master's Thesis, Helsinki University of Technology (2005)

6. Heiskala, M.: Modeling configurable services. Information and Comunication Technology Enabled Commerce, ICTEC (2007)

7. Jiao, J.: Design for Mass Customization by Developing Product Family Architecture, GMRG thesis (1998); Young, M.: The Techincal Writers Handbook. University Science, Mill (1989)

8. Jiao, J., Ma, Q., Tseng, M.M.: Towards high value-added products and services: mass customization and beyond. Technovation 23(10) (2003)

9. Johns, N.: What is this thing called service. European Journal of Marketing 33(9) (1999)

10. Junker, U., Mailharro, D.: Preference Programming: Advanced Problem Solving for Configuration. AI EDAM 17(1), 13-29 (2003)

11. Kotler, P.: Marketing management: analysis, planning implementation and control. Prentice Hall, London (1994)

12. Ma, Q., Tseng, M.M., Yen, B.: A generic model and design representation technique of service products. Technovation 22(1), 15-30 (2002)

13. Martines-tur, V., Peiro, J., Ramos, J.: Linking service structural complexity to customer satisfaction - The moderating role of type ownership. International Journal of Service Industry Management 12(3), 295-306 (2001)

14. Meyer, M.H., DeTorre, A.: PERSPECTIVE: Creating a platform-based approach for developing new services. The Journal of Product Innovation Management (2001)

15. Peters, I., Saidin, H.: IT and mass customization of services: the challenge of inplementation. International Journal of Information Management 20(2), 103-119 (2000)

16. Pine II, B.J.: Mass Customization: The New Frontier in Business Competition. Harvard School Business Press, Boston (1993) 